\title{
Identification of Five Novel Salmonella Typhi-Specific Genes as Markers for Diagnosis of Typhoid Fever Using Single-Gene Target PCR Assays
}

\author{
Yuan Xin Goay, ${ }^{1}$ Kai Ling Chin, ${ }^{1}$ Clarissa Ling Ling Tan, ${ }^{1}$ \\ Chiann Ying Yeoh, ${ }^{1}$ Ja'afar Nuhu Ja'afar, ${ }^{1}$ Abdul Rahman Zaidah, ${ }^{2}$ \\ Suresh Venkata Chinni, ${ }^{3}$ and Kia Kien Phua ${ }^{1}$ \\ ${ }^{1}$ Institute for Research in Molecular Medicine (INFORMM), Universiti Sains Malaysia (USM), Health Campus, \\ 16150 Kubang Kerian, Kelantan, Malaysia \\ ${ }^{2}$ Department of Medical Microbiology and Parasitology, Universiti Sains Malaysia (USM), Health Campus, \\ 16150 Kubang Kerian, Kelantan, Malaysia \\ ${ }^{3}$ Faculty of Applied Sciences, AIMST University, Jalan Bedong-Semeling, 08100 Bedong, Kedah, Malaysia
}

Correspondence should be addressed to Kia Kien Phua; kkphua7@gmail.com

Received 22 June 2016; Revised 27 September 2016; Accepted 18 October 2016

Academic Editor: Hao-Teng Chang

Copyright (C) 2016 Yuan Xin Goay et al. This is an open access article distributed under the Creative Commons Attribution License, which permits unrestricted use, distribution, and reproduction in any medium, provided the original work is properly cited.

\begin{abstract}
Salmonella Typhi (S. Typhi) causes typhoid fever which is a disease characterised by high mortality and morbidity worldwide. In order to curtail the transmission of this highly infectious disease, identification of new markers that can detect the pathogen is needed for development of sensitive and specific diagnostic tests. In this study, genomic comparison of $S$. Typhi with other enteric pathogens was performed, and 6 S. Typhi genes, that is, STY0201, STY0307, STY0322, STY0326, STY2020, and STY2021, were found to be specific in silico. Six PCR assays each targeting a unique gene were developed to test the specificity of these genes in vitro. The diagnostic sensitivities and specificities of each assay were determined using 39 S. Typhi, 62 non-Typhi Salmonella, and 10 non-Salmonella clinical isolates. The results showed that 5 of these genes, that is, STY0307, STY0322, STY0326, STY2020, and STY2021, demonstrated $100 \%$ sensitivity $(39 / 39)$ and $100 \%$ specificity $(0 / 72)$. The detection limit of the 5 PCR assays was $32 \mathrm{pg}$ for STY0322, $6.4 \mathrm{pg}$ for STY0326, STY2020, and STY2021, and $1.28 \mathrm{pg}$ for STY0307. In conclusion, 5 PCR assays using STY0307, STY0322, STY0326, STY2020, and STY2021 were developed and found to be highly specific at single-gene target resolution for diagnosis of typhoid fever.
\end{abstract}

\section{Introduction}

To date, there are more than 2,500 serotypes identified within the Salmonella enterica species [1]. Most are harmless to humans but one serotype, Salmonella enterica subspecies enterica serovar Typhi (S. Typhi), causes typhoid fever, a severe and life-threatening systemic infection in humans. Worldwide, typhoid fever causes 269,000 deaths from 26.9 million new cases each year [2]. Travellers, children, the elderly, and immune-compromised individuals are especially at risk $[3,4]$. The clinical manifestations of typhoid fever are similar to other febrile illnesses. Therefore, diagnosis based on clinical signs and symptoms alone is difficult [5]. The emergence of multidrug-resistant $S$. Typhi strains and development of the typhoid carrier state have further complicated the management of typhoid fever $[6,7]$. Delay in diagnosis and initiation of antibiotic treatment can cause serious clinical complications and fatality [8]. Thus, early and correct laboratory diagnosis of typhoid fever is critical to reduce the morbidity and mortality, as well as curtail transmission of the disease.

DNA-based detection methods, such as polymerase chain reaction (PCR), have proven to be sensitive, specific, and rapid compared to conventional culture-based methods for the diagnosis of many infectious diseases [9-11]. Several target genes have been used for $S$. Typhi identification using 
PCR, such as the $\mathrm{O}$ antigen somatic genes (tyv and prt) [12], $\mathrm{H}$ antigen flagellar gene ( $f l i C$-d) [13], and Vi capsular antigen gene (viaB) [14]. However, these genes cannot stand alone as single $S$. Typhi-specific diagnostic marker since they are not specific to S. Typhi and are also found in other Salmonella serotypes. Thus, these markers provide provisional rather than differential diagnosis of typhoid fever. For example, the fliC-d gene of $S$. Typhi shares the same nucleic acid sequence as $S$. Muenchen [15]; the prt gene is present in $S$. Typhi, $S$. Paratyphi A, and S. Enteritidis [12]; and the viaB gene is found not only in $S$. Typhi but also in $S$. Dublin, a few strains of $S$. Paratyphi C [16] and Citrobacter freundii [17]. Due to the lack of specificity of these target genes, a combination of different pairs of primers using multiplex PCR [18] or nested PCR [19] are needed to increase the sensitivity and specificity of the PCR diagnostic test. This, however, will increase the cost, time, and complexity of the laboratory diagnosis.

Diagnostic markers which can detect pathogens at singlegene target resolution could lead to a simpler, cost-effective, and more functional DNA-based detection method since less primers are needed for target detection. Many approaches, such as subtractive hybridization [20], next generation sequencing [21], and microarray [22] techniques, have been used to identify genes that are specific or unique to a pathogen. However, these high-end technologies are cumbersome and expensive and sometimes yield false negative or false positive results [23]. Since bacterial genome databases have expanded tremendously over the past decade and advancement in computing technologies has made nucleic acid sequence alignment services readily accessible at NCBI, in silico comparative hybridization approach coupled with in vitro PCR (wet-lab) validation is sufficient to facilitate the translation of genomic data into diagnostic marker discoveries. In this study, a low-cost and simple attempt was made to identify new DNA diagnostic markers specific for $S$. Typhi by utilizing genome data (stored in NCBI databases) and nucleic acid sequence alignment tools (BLASTn) that are readily available in the public domain. The diagnostic sensitivities and specificities of the primers designed for amplifying whole gene sequences can be validated using a panel of confirmed bacteria isolates selected from $S$. Typhi, non-Typhi Salmonella, and non-Salmonella clinical isolates. To serve as a control for the PCR reaction, 16S rRNA gene, that is ubiquitous among bacteria species, can be used as a PCR amplification control [24].

\section{Materials and Methods}

2.1. Bacterial Strains. A total of 111 bacteria isolates including 39 S. Typhi, 62 non-Typhi Salmonella serotypes, and 10 non-Salmonella strains were used in this study. S. Typhi strains consisted of $1 \mathrm{~S}$. Typhi reference strains (ATCC 7251) and 38 different pulsed-field types (PFTs) representing all strains in the state of Kelantan in Malaysia. These 38 PFTs were the result of screening 279 S. Typhi clinical isolates using pulsed-field gel electrophoresis (PFGE) [25]. Non-Typhi Salmonella serotypes were closely related Salmonella species made up of 26 different serotypes (Table 2) and 10 ATCC strains including $S$. Paratyphi A (ATCC
9150), S. Paratyphi B (ATCC BAA 1250), S. Paratyphi C (ATCC 9068), S. Enteritidis (ATCC 13076), S. Typhimurium (ATCC 14028), S. Weltevreden (NCTC 6534), S. Agona (ATCC 51957), S. Heidelberg (ATCC 8326), S. Poona (ATCC 04840), and $S$. Braenderup (ATCC BAA-664). In addition, 10 other non-Salmonella strains such as Shigella dysenteriae, Shigella flexneri, Shigella boydii, Shigella sonnei, Vibrio cholera, Enterohemorrhagic E. coli, Enteropathogenic E. coli, Aeromonas hydrophila, Yersinia enterocolitica, and Klebsiella pneumonia were also included. All clinical strains were procured from the Department of Clinical Microbiology and Parasitology, Hospital Universiti Sains Malaysia (HUSM), Kelantan, Malaysia, and the Biobank of the Institute for Research in Molecular Medicine (INFORMM), Kelantan, Malaysia. All bacteria strains were stored in glycerol stocks at $-80^{\circ} \mathrm{C}$ until being ready for use. Ethical clearance for this project was obtained from the Human Research Ethics Committee, Universiti Sains Malaysia (reference number USMKK/PPP/JEPeM [235.3.(16)]).

2.2. Culture Conditions and Confirmation Tests. All bacteria isolates used in this study were confirmed by traditional culture, biochemical, and serotyping methods as described in ISO6579 with some modifications. Bacteria isolates were revived from frozen glycerol stocks by pipetting $100 \mu \mathrm{L}$ thawed cells into $10 \mathrm{~mL}$ nutrient broth and incubated at $37^{\circ} \mathrm{C}$ for 18 hours in an orbital shaker at $200 \mathrm{rpm}$. The bacteria were streaked on Xylose Lysine Deoxycholate (XLD) selective agar and incubated at $37^{\circ} \mathrm{C}$ for 18 hours. Colonies grown on the agar were tested with a panel of biochemical tests, including Triple Sugar Iron (TSI), urease, Methyl Red Voges Proskauer (MRVP), citrate, and indole tests. Suspected Salmonella isolates were then sent to the Salmonella Reference Centre, Institute for Medical Research (IMR), Malaysia, to confirm their serotypes using specific antisera and latex agglutination method.

2.3. Identification of S. Typhi-Specific Genes Using Bioinformatics (In Silico). Full genome sequence of S. Typhi CT18 (GenBank accession number AL513382) was downloaded from the National Center for Biotechnology Information database (NCBI) and used as the reference genome. The 2 plasmids, namely, $\mathrm{pHCM} 1$ and $\mathrm{pHCM} 2$, which resided in S. Typhi CT18 were excluded since plasmids are genetically unstable. The 6 complete $S$. Typhi whole-genome sequences available in NCBI were used for data mining. They comprised CT18 (Genbank accession number AL513382) [27], Ty2 (Genbank accession number AE014613) [28], Pstx-12 (Genbank accession number CP003278) [29], Ty21a (Genbank accession number CP002099) [30], B/SF/13/03/195 (Genbank accession number CP012151) [31], and PM016/13 (Genbank accession number CP012091) [32]. In order to ascertain whether the genomic regions were conserved and specific to $S$. Typhi, the nucleotide Basic Local Alignment Search Tool (BLASTn), a free online software for nucleic acid analysis, was used to compare the whole-genome sequence of S. Typhi CT18 with the other 5 complete S. Typhi genomes and other bacteria genomes in the NCBI database (https://blast.ncbi.nlm.nih.gov/Blast.cgi). Genes found in 


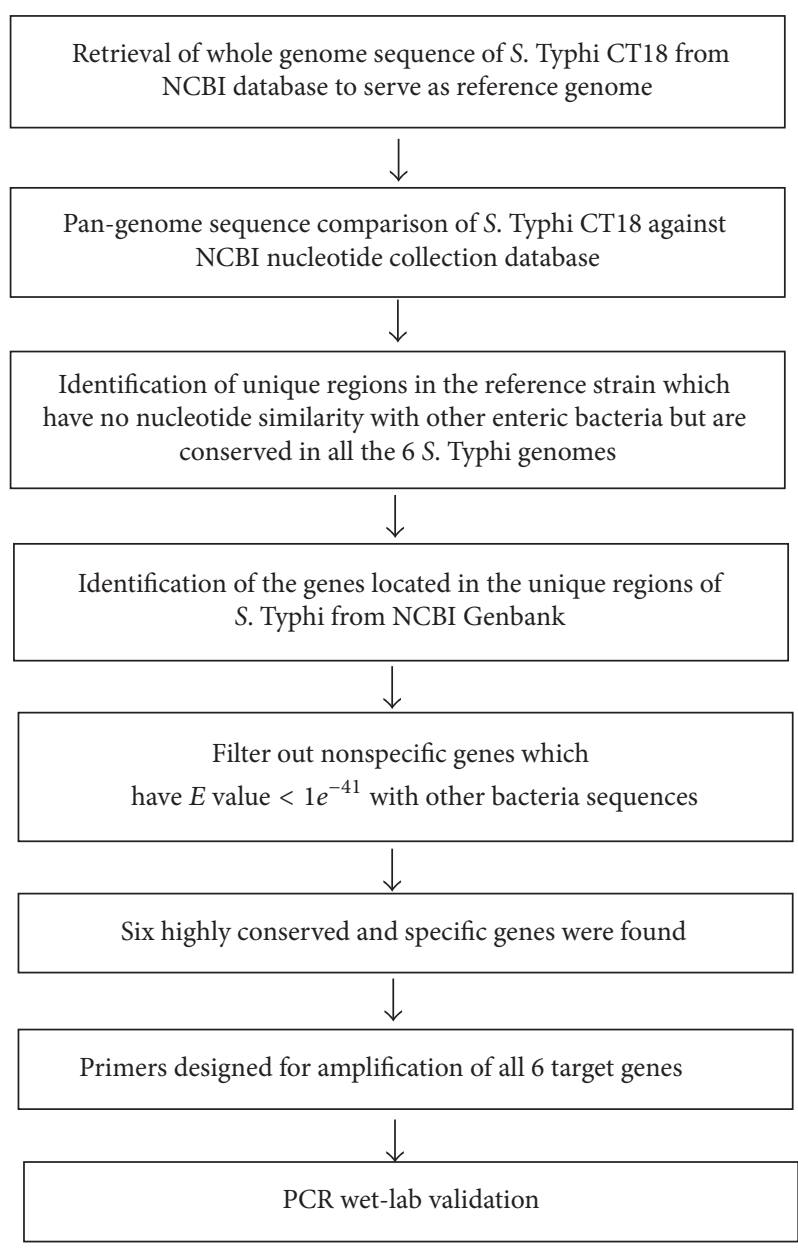

FIGURE 1: Experimental workflow describing the comparative genomic and wet-lab approaches used to identify and validate $S$. Typhi-specific DNA diagnostic markers.

unique regions which have no nucleotide similarity with other enteric organisms were identified and retrieved from the Genebank of NCBI. These genes were further screened individually using similarity searches against the NCBI nonredundant nucleotide $(\mathrm{nr} / \mathrm{nt})$ database to reconfirm their specificities. The program was set for "somewhat similar sequences search," which allowed nucleotide sequence matching down to 7 bases (the smaller the nucleotide size, the more sensitive the result). Realizing the high genome similarity among the enteric pathogens and the possibility that different geographical areas may result in different bacterial genotypes, only genes which have $100 \%$ sequence conservation (an $E$-value threshold $=0.0$ ) in all 6 complete $S$. Typhi genomes and had little or no similarity (E-value threshold $\geq 1 e^{-41}$ ) to other bacterial sequences in the NCBI database were considered as potential targets and were subjected to wet-lab analysis. The experimental pipeline is as shown in Figure 1.

2.4. Design of Oligonucleotide Primers for PCR Amplification. Primers were designed manually to amplify the $S$. Typhispecific genes identified previously, including the start and the stop codons. A pair of primers specific for 16S rRNA gene amplification as described by Marchesi and colleagues [24] were also incorporated into each PCR assay to serve as an internal amplification control (IAC). This is a universal gene target which is highly conserved in bacteria [24]. All primers were synthesized by Integrated DNA Technologies (IDT) Pte. Ltd., Malaysia.

2.5. Template DNA Extraction. DNA from all bacteria isolates were extracted using DNeasy Blood \& Tissue kit ${ }^{\circledR}$ (Qiagen, USA) according to the manufacturer's instructions. The purity and concentration of the extracted DNA were determined using Nanodrop Spectrophotometer ND-1000 (Thermo Fisher Scientific, USA). DNA concentration was measured from the absorbance at $260 \mathrm{~nm}$. Ratio of the absorbance at 260 and $280 \mathrm{~nm}\left(A_{260 / 280}\right)$ and ratio of the absorbance at 230 and $260 \mathrm{~nm}\left(A_{230 / 260}\right)$ were used to evaluate the DNA quality. The extracted DNAs were diluted to a final stock concentration of $50 \mathrm{ng} / \mu \mathrm{L}$ using ultrapure water and stored at $-20^{\circ} \mathrm{C}$ until ready for PCR amplification.

2.6. Optimization of PCR. Each PCR assay was optimized using a modified Taguchi method as described by Cobb and Clarkson [33]. The effects and interactions of the 4 main PCR components (IAC primers, S. Typhi-specific gene primers, $\mathrm{MgCl}_{2}$, and annealing temperatures) each at 3 different levels (IAC primers: $0.05,0.10$, and $0.15 \mu \mathrm{M} ; S$. Typhi primers: $1.00,1.50$, and $2.00 \mu \mathrm{M} ; \mathrm{MgCl}_{2}: 2.00,2.50$, and $3.00 \mathrm{mM}$, and annealing temperatures: 50,55 , and $60^{\circ} \mathrm{C}$ ) were investigated in a balanced orthogonal array of 9 experimental combinations. The PCR amplifications were carried out in a total reaction volume of $20 \mu \mathrm{L}$, and the PCR products were analysed on a $1.2 \%(\mathrm{w} / \mathrm{v})$ agarose gel containing $\mathrm{SYBR}^{\circledR}$ Safe DNA Gel Stain (Invitrogen, USA), visualized using a bluelight transilluminator (Syngene, UK).

2.7. Analytical Specificities of Genes Unique to S. Typhi. Analytical specificities of the PCR assays were assessed by running each PCR assay on a panel of bacteria strains consisting of 39 S. Typhi, 62 non-Typhi Salmonella, and 10 non-Salmonella clinical isolates.

2.8. Detection Limit of the PCR Assays. Detection limit of the PCR assays was defined as the minimum amount of $S$. Typhi DNA (ng/ $\mu \mathrm{L})$ that yielded positive PCR amplicons. The assay sensitivities were determined by amplification of a 5fold serial dilution of $S$. Typhi ATCC 7251 DNA, ranging from $50 \mathrm{ng}$ to $25.6 \mathrm{fg}$. Two microliters of the DNA was subjected to PCR amplification. The analytical sensitivity was indicated by the presence of visible PCR product bands on the agarose gel using the transilluminator as described above.

2.9. DNA Sequencing. To confirm the PCR products were indeed derived from the $S$. Typhi strains, PCR amplicons from all assays produced using Phusion ${ }^{\circledR}$ High-Fidelity DNA Polymerase (New England Biolabs, USA) were purified and sent to First BASE Laboratories Pte. Ltd., Malaysia, for sequencing. The resultant nucleotide sequences were compared with the reference $S$. Typhi CT18 gene sequences in NCBI using BioEdit software. 
TABLE 1: List of primers targeting S. Typhi-specific genes for the development of 6 PCR assays.

\begin{tabular}{lccc}
\hline Target genes & Primer labels & Primer sequences $\left(5^{\prime}-3^{\prime}\right)$ & Target lengths $(\mathrm{bp})$ \\
\hline STY0201 & $0201 \mathrm{~F}$ & ATGCTTTTAAAAAACACAACATGG & 1176 \\
& $0201 \mathrm{R}$ & TTACGGATAGGTGATTGAAAATTG & \\
STY0307 & $0307 \mathrm{~F}$ & ATGAAACCTTTATTCTCAGTGC & 495 \\
& $0307 \mathrm{R}$ & TTAGCGTAATTCCCAGAACC & \\
STY0322 & $0322 \mathrm{~F}$ & ATGAAATATAAAAAAATAAGAG & \\
& $0322 \mathrm{R}$ & CTATGGATTCATTTCCATTTC & 261 \\
STY0326 & $0326 \mathrm{~F}$ & ATGAATACGAATAATTCACC & \\
& $0326 \mathrm{R}$ & TTACCCTCCCCATGTCAC & 429 \\
STY2020 & $2020 \mathrm{~F}$ & ATGCCTGTTATGCATAATTG & \\
& $2020 \mathrm{R}$ & TTATGCTGTTAACGAGTCGTC & 732 \\
STY2021 & $2021 \mathrm{~F}$ & ATGAGTTTAGCGCAGCCTAAATCC & \\
& $2021 \mathrm{R}$ & TTAGAAGTCTCCTGCCTGGAAAC & 1362 \\
\hline
\end{tabular}

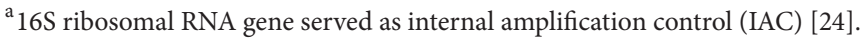

F represents forward primer.

$\mathrm{R}$ represents reverse primer.

\section{Results}

Using the bioinformatic method for whole-genome comparison (Figure 1), 6 potential diagnostic markers with NCBI locus tags, STY0201, STY0307, STY0322, STY0326, STY2020, and STY2021, were found. They exhibit 100\% query coverage and identity $(E$-value $=0)$ with all $6 S$. Typhi gene sequences but had low or no significant similarity $\left(E\right.$-value $\left.\geq 1 e^{-41}\right)$ with other enteric bacteria nucleotide sequences as of 11 March 2016. These genes were found to be (bioinformatically) highly conserved and specific and thus were selected for further wetlab validation using PCR method. The primers designed to amplify these selected genes are shown in Table 1.

The results showed that all 6 designed primer pairs successfully amplified their target genes with amplicon sizes of $1176,495,678,261,429$, and 732 bps, respectively. DNA sequencing results of the amplicons showed $100 \%$ identity with their corresponding S. Typhi genes, confirming the fidelity and sensitivity of the primers.

The 6 single-gene target PCR assays were then optimized using Taguchi method with the incorporation of IAC which targeted the 16S rRNA gene. The optimized master mix for the PCR assays targeting STY0201, STY0307, and STY2020 genes consisted of 1x Green GoTaq Flexi Buffer, $2.0 \mathrm{mM} \mathrm{MgCl} 2,0.2 \mathrm{mM}$ dNTPs, $1.5 \mu \mathrm{M}$ S. Typhi-specific gene primers, $0.10 \mu \mathrm{M}$ IAC primers, $0.75 \mathrm{U}$ GoTaq Flexi DNA Polymerase (Promega, USA), and 5\% glycerol in a total volume of $20 \mu \mathrm{L}$. Two microliters of test DNA ( $50 \mathrm{ng} / \mu \mathrm{L})$ was added to the master mix and amplified using the following optimized thermal-cycling parameters: initial denaturation at $95^{\circ} \mathrm{C}$ for $1 \mathrm{~min}$, followed by 30 cycles elongation at $95^{\circ} \mathrm{C}$ for $30 \mathrm{~s}, 55^{\circ} \mathrm{C}$ for $30 \mathrm{~s}, 72^{\circ} \mathrm{C}$ for $1 \mathrm{~min}$ and a final extension at $72^{\circ} \mathrm{C}$ for $5 \mathrm{~min}$. Similar PCR conditions were used for amplification of STY0322, STY0326, and STY2021 genes except for the concentration of $\mathrm{MgCl}_{2}$ and IAC primers which were set at $3.0 \mathrm{mM}$ and $0.15 \mu \mathrm{M}$, respectively. The optimal annealing temperature was set at $50^{\circ} \mathrm{C}$. Under these conditions, the IAC primer pair produced an amplicon of $1,362 \mathrm{bp}$ for all bacteria isolates tested (111/111).

The optimized PCR assays for STY0307, STY0322, STY0326, STY2020, and STY2021 correctly identified all $S$. Typhi (39/39) isolates, whereas none of the non-Typhi Salmonella (0/62) and none of the non-Salmonella (0/10) isolates were detected. This showed a $100 \%$ sensitivity and $100 \%$ specificity for the PCR assays (Table 2) and indicate that the 5 genes were unique to $S$. Typhi (Figures 2, 3, and 4).

The results of serial dilution of $S$. Typhi genomic DNA showed that the detection limit of the optimized PCR assays was $32 \mathrm{pg}$ for gene STY0322, 6.4 pg for genes STY0326, STY2020, and STY2021, and 1.28 pg for gene STY0307.

Although gene STY0201 exhibited 100\% sensitivity (detection of 39/39 S. Typhi isolates), it showed crossreactivity with $S$. Oslo and $S$. Kissi (Table 2), resulting in a specificity of only $97.2 \%$ (detection of $2 / 72$ of non-Typhi isolates). Sequencing of their PCR products showed a substitution of nucleotide $\mathrm{C} \rightarrow \mathrm{T}$ at position 89 and $\mathrm{T} \rightarrow$ C at positions 354 and 1,026 for both $S$. Kissi and S. Oslo. The sequence variation between $S$. Kissi and $S$. Oslo with the S. Typhi CT18 reference genome was very small (only 3 nucleotide differences), indicating that the false positive results were due to sequence similarity among themselves.

\section{Discussion}

The diagnosis of typhoid fever based on clinical signs and symptoms is often ambiguous, while phenotypic detection of $S$. Typhi bacteria based on biochemical and serotyping methods is laborious and time-consuming. Thus, rapid molecular detection methods, such as nucleic acid-based amplification, such as PCR assay, is critically needed to help diagnose this contagious disease. Development of this test requires diagnostic markers that are sensitive and specific. 
TABLE 2: Evaluation of the specificities of the 6 target genes for identification of $S$. Typhi using PCR (total of 111 clinical isolates).

\begin{tabular}{|c|c|c|c|c|c|c|}
\hline \multirow{2}{*}{ Test bacteria strains } & \multicolumn{6}{|c|}{ Positive PCR amplification for each target gene } \\
\hline & STY0201 & STY0307 & STY0322 & STY0326 & STY2020 & STY2021 \\
\hline S. Typhi $(n=39)$ & $39 / 39$ & $39 / 39$ & $39 / 39$ & $39 / 39$ & $39 / 39$ & $39 / 39$ \\
\hline$S$. Paratyphi A $(n=10)$ & $0 / 10$ & $0 / 10$ & $0 / 10$ & $0 / 10$ & $0 / 10$ & $0 / 10$ \\
\hline$S$. Paratyphi B $(n=10)$ & $0 / 10$ & $0 / 10$ & $0 / 10$ & $0 / 10$ & $0 / 10$ & $0 / 10$ \\
\hline$S$. Paratyphi C $(n=1)$ & $0 / 1$ & $0 / 1$ & $0 / 1$ & $0 / 1$ & $0 / 1$ & $0 / 1$ \\
\hline$S$. Enteritidis $(n=10)$ & $0 / 10$ & $0 / 10$ & $0 / 10$ & $0 / 10$ & $0 / 10$ & $0 / 10$ \\
\hline$S$. Typhimurium $(n=10)$ & $0 / 10$ & $0 / 10$ & $0 / 10$ & $0 / 10$ & $0 / 10$ & $0 / 10$ \\
\hline$S$. Weltevreden $(n=1)$ & $0 / 1$ & $0 / 1$ & $0 / 1$ & $0 / 1$ & $0 / 1$ & $0 / 1$ \\
\hline S. Agona $(n=1)$ & $0 / 1$ & $0 / 1$ & $0 / 1$ & $0 / 1$ & $0 / 1$ & $0 / 1$ \\
\hline S. Hadar $(n=1)$ & $0 / 1$ & $0 / 1$ & $0 / 1$ & $0 / 1$ & $0 / 1$ & $0 / 1$ \\
\hline S. Heidelberg $(n=1)$ & $0 / 1$ & $0 / 1$ & $0 / 1$ & $0 / 1$ & $0 / 1$ & $0 / 1$ \\
\hline S. Poona $(n=1)$ & $0 / 1$ & $0 / 1$ & $0 / 1$ & $0 / 1$ & $0 / 1$ & $0 / 1$ \\
\hline$S$. Braenderup $(n=1)$ & $0 / 1$ & $0 / 1$ & $0 / 1$ & $0 / 1$ & $0 / 1$ & $0 / 1$ \\
\hline S. Albany $(n=1)$ & $0 / 1$ & $0 / 1$ & $0 / 1$ & $0 / 1$ & $0 / 1$ & $0 / 1$ \\
\hline S. Oslo $(n=1)$ & $1 / 1$ & $0 / 1$ & $0 / 1$ & $0 / 1$ & $0 / 1$ & $0 / 1$ \\
\hline S. Kibi $(n=1)$ & $0 / 1$ & $0 / 1$ & $0 / 1$ & $0 / 1$ & $0 / 1$ & $0 / 1$ \\
\hline$S$. Newport $(n=1)$ & $0 / 1$ & $0 / 1$ & $0 / 1$ & $0 / 1$ & $0 / 1$ & $0 / 1$ \\
\hline S. Tshiongwe $(n=1)$ & $0 / 1$ & $0 / 1$ & $0 / 1$ & $0 / 1$ & $0 / 1$ & $0 / 1$ \\
\hline S. Uppsala $(n=1)$ & $0 / 1$ & $0 / 1$ & $0 / 1$ & $0 / 1$ & $0 / 1$ & $0 / 1$ \\
\hline S. Richmond $(n=1)$ & $0 / 1$ & $0 / 1$ & $0 / 1$ & $0 / 1$ & $0 / 1$ & $0 / 1$ \\
\hline S. Bardo $(n=1)$ & $0 / 1$ & $0 / 1$ & $0 / 1$ & $0 / 1$ & $0 / 1$ & $0 / 1$ \\
\hline S. Emek $(n=1)$ & $0 / 1$ & $0 / 1$ & $0 / 1$ & $0 / 1$ & $0 / 1$ & $0 / 1$ \\
\hline$S$. Kissi $(n=1)$ & $1 / 1$ & $0 / 1$ & $0 / 1$ & $0 / 1$ & $0 / 1$ & $0 / 1$ \\
\hline S. Virchow $(n=1)$ & $0 / 1$ & $0 / 1$ & $0 / 1$ & $0 / 1$ & $0 / 1$ & $0 / 1$ \\
\hline$S$. Bordeaux $(n=1)$ & $0 / 1$ & $0 / 1$ & $0 / 1$ & $0 / 1$ & $0 / 1$ & $0 / 1$ \\
\hline$S$. Regent $(n=1)$ & $0 / 1$ & $0 / 1$ & $0 / 1$ & $0 / 1$ & $0 / 1$ & $0 / 1$ \\
\hline$S$. Java $(n=1)$ & $0 / 1$ & $0 / 1$ & $0 / 1$ & $0 / 1$ & $0 / 1$ & $0 / 1$ \\
\hline$S$. Farsta $(n=1)$ & $0 / 1$ & $0 / 1$ & $0 / 1$ & $0 / 1$ & $0 / 1$ & $0 / 1$ \\
\hline Shigella dysenteriae $(n=1)$ & $0 / 1$ & $0 / 1$ & $0 / 1$ & $0 / 1$ & $0 / 1$ & $0 / 1$ \\
\hline Shigella flexneri $(n=1)$ & $0 / 1$ & $0 / 1$ & $0 / 1$ & $0 / 1$ & $0 / 1$ & $0 / 1$ \\
\hline Shigella sonnei $(n=1)$ & $0 / 1$ & $0 / 1$ & $0 / 1$ & $0 / 1$ & $0 / 1$ & $0 / 1$ \\
\hline Shigella boydii $(n=1)$ & $0 / 1$ & $0 / 1$ & $0 / 1$ & $0 / 1$ & $0 / 1$ & $0 / 1$ \\
\hline Vibrio cholerae $(n=1)$ & $0 / 1$ & $0 / 1$ & $0 / 1$ & $0 / 1$ & $0 / 1$ & $0 / 1$ \\
\hline Enterohemorrhagic E. coli $(n=1)$ & $0 / 1$ & $0 / 1$ & $0 / 1$ & $0 / 1$ & $0 / 1$ & $0 / 1$ \\
\hline Enteropathogenic E. coli $(n=1)$ & $0 / 1$ & $0 / 1$ & $0 / 1$ & $0 / 1$ & $0 / 1$ & $0 / 1$ \\
\hline Aeromonas hydrophila $(n=1)$ & $0 / 1$ & $0 / 1$ & $0 / 1$ & $0 / 1$ & $0 / 1$ & $0 / 1$ \\
\hline Yersinia enterocolitica $(n=1)$ & $0 / 1$ & $0 / 1$ & $0 / 1$ & $0 / 1$ & $0 / 1$ & $0 / 1$ \\
\hline Klebsiella pneumoniae $(n=1)$ & $0 / 1$ & $0 / 1$ & $0 / 1$ & $0 / 1$ & $0 / 1$ & $0 / 1$ \\
\hline
\end{tabular}

This is the first report on the use of genes STY0307, STY0322, STY0326, STY2020, and STY2021 as S. Typhispecific diagnostic markers. Unlike other S. Typhi PCR targets that were selected based on immunological properties, these genes are individually highly specific for $S$. Typhi and therefore can be used as single-gene target PCR assays without the need for nested or multiplex PCR. Also, these targets are whole gene sequences (from start to stop codon for the purpose of whole gene amplification) unlike other diagnostic markers which are only partial gene sequences. The idea of using this strategy is that if the whole gene sequence is specific to the bacteria then primers can be designed at any location of the gene. Thus, these gene sequences not only serve as specific targets for PCR assay, but also are suitable for more advance diagnostic tests that require multiple DNA sites, such as loop-mediated isothermal amplification (LAMP) and strand displacement amplification (SDA) which requires multiple primer annealing sites [34]. These genes could be utilized for the development of innovative Point-of-Care (POC) diagnostics to address the need for low-cost, simple, rapid, and accurate diagnostics for low resource settings.

The gene STY0201 has been used as a PCR target, and the PCR assays that were developed based on this gene were reported to be $100 \%$ sensitivity and specificity $[35,36]$. 


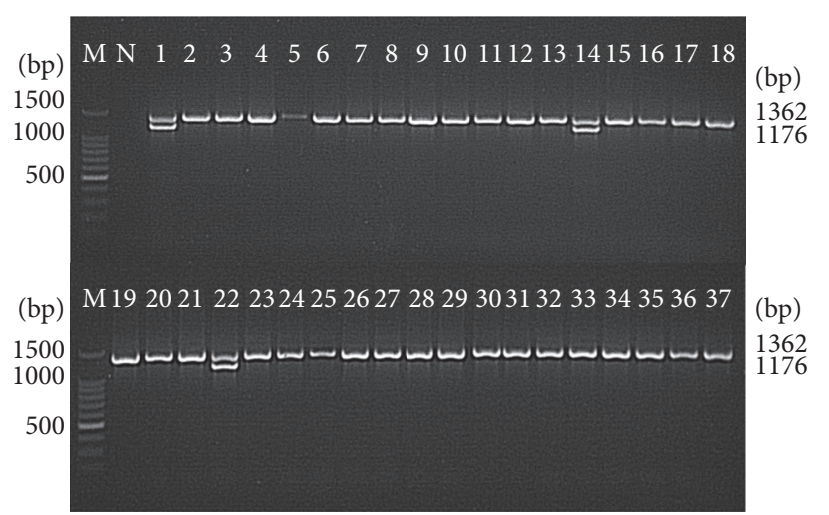

(a)

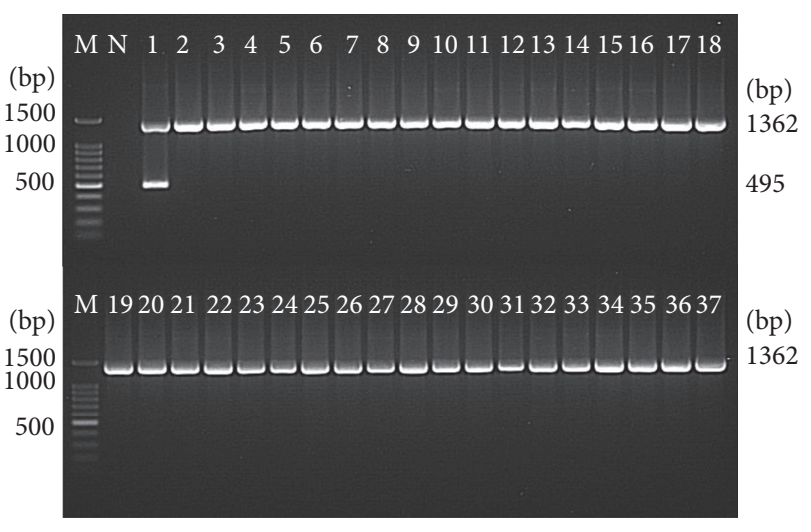

(b)

Figure 2: Analytical specificity of the PCR assay for detection of (a) STY0201 and (b) STY0307 genes (representative figures). Lane: M = 100 bp DNA ladder (Promega); $N=$ negative control; $1=S$. Typhi; $2=S$. Paratyphi A; $3=S$. Paratyphi B; $4=S$. Paratyphi C; $5=S$. Enteritidis; $6=S$. Typhimurium; $7=S$. Weltevreden; $8=S$. Agona; $9=S$. Heidelberg; $10=S$. Poona; $11=S$. Hadar; $12=S$. Braenderup; $13=S$. Albany; 14 $=S$. Oslo; $15=S$. Kibi; $16=S$. Newport; $17=S$. Tshiongwe; $18=S$. Uppsala; $19=S$. Richmond; $20=S$. Bardo; $21=S$. Emek; $22=S$. Kissi; $23=$ S. Virchow; $24=$ S. Bordeaux; $25=$ S. Regent $26=$ S. Java; $27=$ S. Farsta $28=$ Shigella dysenteriae $; 29=$ Shigella flexneri $30=$ Shigella sonnei; $31=$ Shigella boydii; 32 = Vibrio cholerae; 33 = Enterohemorrhagic Escherichia coli; $34=$ Enteropathogenic Escherichia coli; $35=$ Aeromonas hydrophila; 36 = Yersinia enterocolitica; and 37 = Klebsiella pneumonia. The PCR amplicon sizes for genes 16S rRNA, STY0201, and STY0307 were $1326 \mathrm{bp}, 1176 \mathrm{bp}$, and $732 \mathrm{bp}$, respectively.

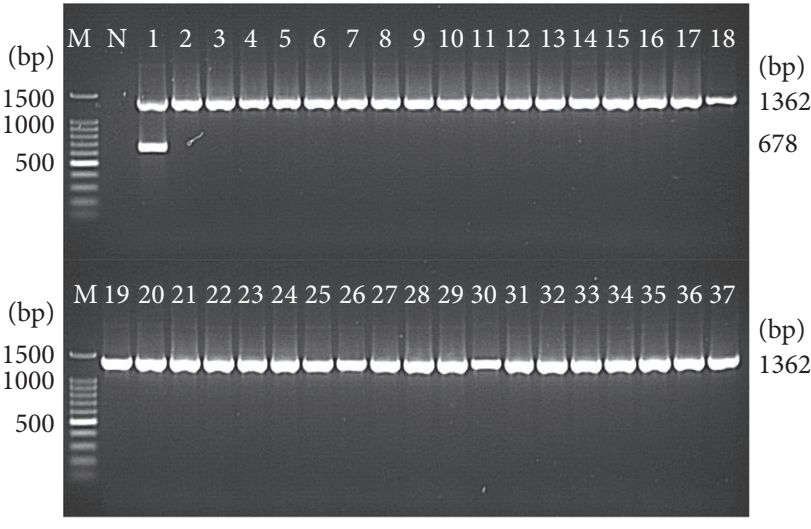

(a)

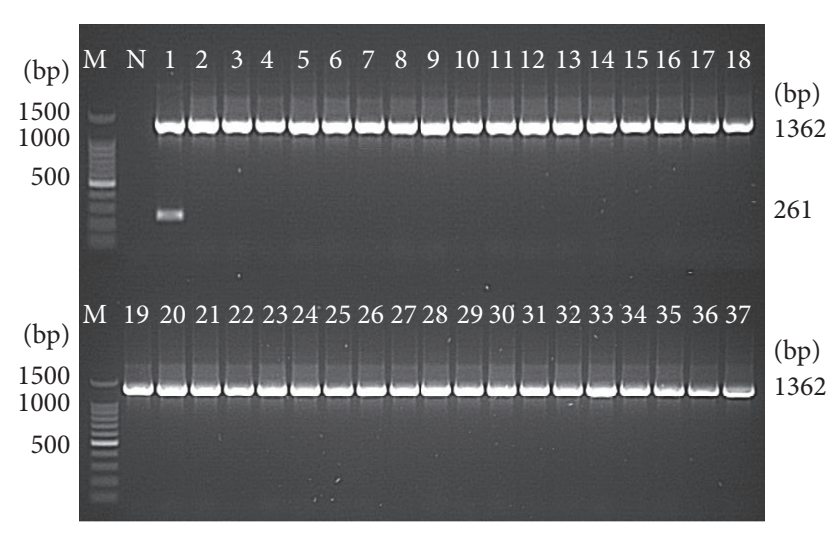

(b)

FIGURE 3: Analytical specificity of the PCR assay for detection of (a) STY0322 and (b) STY0326 genes, respectively (representative gels). Lane: $\mathrm{M}=100$ bp DNA ladder (Promega) $\mathrm{N}=$ negative control; $1=S$. Typhi; $2=S$. Paratyphi A; $3=S$. Paratyphi B; $4=S$. Paratyphi C; $5=S$. Enteritidis; $6=S$. Typhimurium; $7=S$. Weltevreden; $8=S$. Agona; $9=S$. Heidelberg; $10=S$. Poona; $11=S$. Hadar; $12=S$. Braenderup; $13=$ $S$. Albany; $14=S$. Oslo; $15=S$. Kibi; $16=S$. Newport; $17=S$. Tshiongwe; $18=S$. Uppsala; $19=S$. Richmond; $20=S$. Bardo; $21=S$. Emek; 22 $=$ S. Kissi; $23=$ S. Virchow; $24=$ S. Bordeaux; $25=$ S. Regent; $26=$ S. Java; $27=$ S. Farsta $28=$ Shigella dysenteriae $; 29=$ Shigella flexneri $; 0$ = Shigella sonnei; 31 = Shigella boydii; 32 = Vibrio cholerae; 33 = Enterohemorrhagic Escherichia coli; 34 = Enteropathogenic Escherichia coli; 35 = Aeromonas hydrophila; 36 = Yersinia enterocolitica; and $37=$ Klebsiella pneumonia. The PCR amplicon sizes for genes 16S rRNA, STY0322, and STY0326 were 1,326 bp, $678 \mathrm{bp}$, and $261 \mathrm{bp}$, respectively.

However, this study found that this gene was only $97.2 \%$ specific and cross-reacted with $S$. Oslo and $S$. Kissi. The incorrect bioinformatic prediction of the specificity of gene STY0201 may be due to the incomplete genome sequence available for the 2 bacteria in the NCBI database that limit the matching accuracy of the BLASTn search. This is a limitation of the alignment-based marker identification method, as it relies on the availability of a complete genome sequence. Thus, whenever new sequence data becomes available for the target organism, the bioinformatic analysis should be repeated to align the current diagnostic markers with the new gene sequence to ensure the specificity.

The other 5 genes identified in this study showed no sequence homology to proteins of known function using protein BLAST (BLASTp) programs. Genes STY0307, STY0322, and STY0326 encode for hypothetical proteins, while genes STY2020 and STY2021 encode for putative bacteriophage proteins. Interestingly, genes STY0307, STY0322, and STY0326 are located in the Salmonella Pathogenicity Island 6 (SPI-6). Yet, their role in bacteria virulence and 
TABLE 3: Details of the 5 target genes and their description, antigenicity prediction, protein coverage, and identity with $S$. Paratyphi A.

\begin{tabular}{|c|c|c|c|c|c|c|}
\hline Number & $\begin{array}{c}\text { Target genes } \\
\text { (NCBI locus tag) }\end{array}$ & Gene description & $\begin{array}{c}\text { GC content } \\
(\%) \\
\end{array}$ & $\begin{array}{l}\text { Antigenicity } \\
\text { prediction }^{*}\end{array}$ & $\begin{array}{c}\text { Protein coverage with } S \text {. } \\
\text { Paratyphi A }(\%)\end{array}$ & $\begin{array}{c}\text { Protein identity with } S . \\
\text { Paratyphi A (\%) } \\
\end{array}$ \\
\hline 1 & STY0307 & $\begin{array}{l}\text { Hypothetical } \\
\text { protein }\end{array}$ & 43 & 0.66 & 0 & 0 \\
\hline 2 & STY0322 & $\begin{array}{l}\text { Hypothetical } \\
\text { protein }\end{array}$ & 29 & 0.37 & 21 & 33 \\
\hline 3 & STY0326 & $\begin{array}{l}\text { Conserved } \\
\text { hypothetical } \\
\text { protein }\end{array}$ & 37 & 0.79 & 0 & 0 \\
\hline 4 & STY2020 & $\begin{array}{c}\text { Putative } \\
\text { bacteriophage } \\
\text { protein }\end{array}$ & 42 & 0.66 & 0 & 0 \\
\hline 5 & STY2021 & $\begin{array}{c}\text { Putative } \\
\text { bacteriophage } \\
\text { protein }\end{array}$ & 42 & 0.27 & 0 & 0 \\
\hline
\end{tabular}

*Antigenicity of the $S$. Typhiproteins predicted using SCRATCH Protein Prediction software [26].

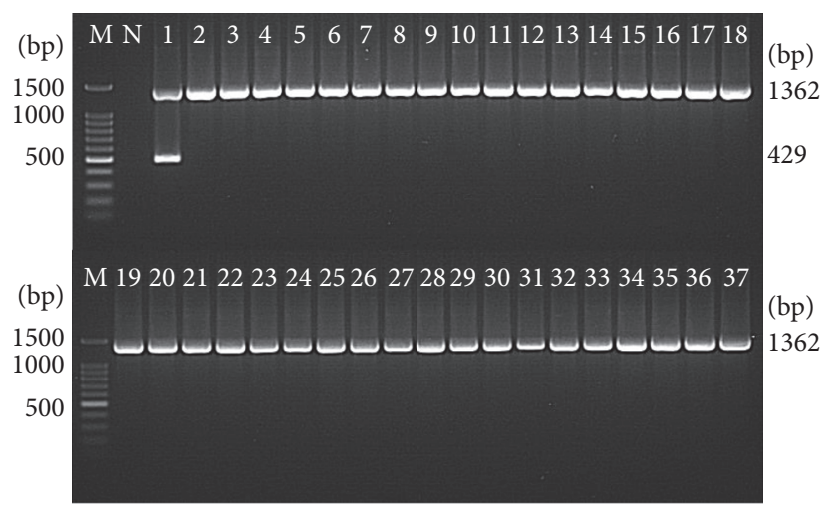

(a)

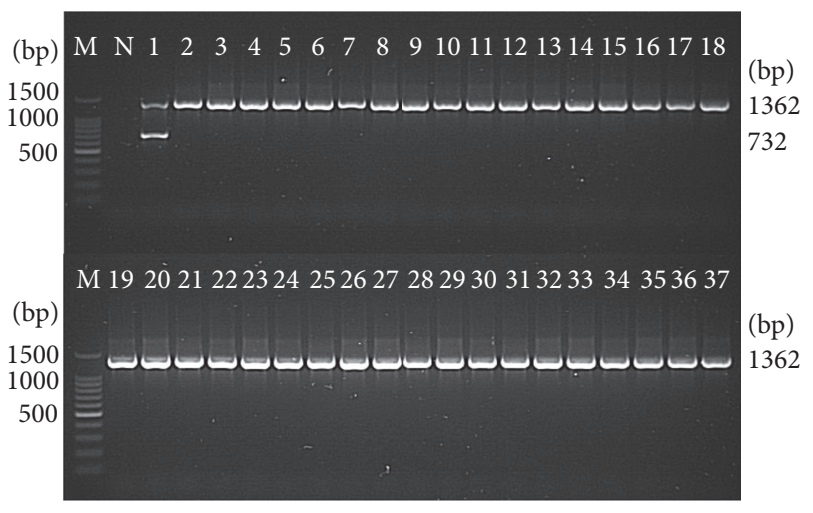

(b)

Figure 4: Analytical specificity of the PCR assay for detection of (a) STY2020 and (b) STY2021 genes, respectively (representative figures). Lane: $\mathrm{M}=100 \mathrm{bp}$ DNA ladder (Promega); $\mathrm{N}=$ negative control; $1=S$. Typhi; $2=S$. Paratyphi A; $3=S$. Paratyphi B; $4=S$. Paratyphi C; $5=$ $S$. Enteritidis; $6=S$. Typhimurium; $7=S$. Weltevreden; $8=S$. Agona; $9=S$. Heidelberg; $10=S$. Poona; $11=S$. Hadar; $12=S$. Braenderup; 13 $=S$. Albany; $14=S$. Oslo; $15=S$. Kibi; $16=S$. Newport; $17=S$. Tshiongwe; $18=S$. Uppsala; $19=S$. Richmond; $20=S$. Bardo; $21=S$. Emek; 22 $=S$. Kissi; $23=$ S. Virchow; $24=$ S. Bordeaux; $25=$ S. Regent; $26=$ S. Java; $27=$ S. Farsta; $28=$ Shigella dysenteriae; $29=$ Shigella flexneri 30 = Shigella sonnei; 31 = Shigella boydii; 32 = Vibrio cholerae; 33 = Enterohemorrhagic Escherichia coli; 34 = Enteropathogenic Escherichia coli; 35 = Aeromonas hydrophila; 36 = Yersinia enterocolitica; and 37 = Klebsiella pneumonia . The PCR amplicon sizes for genes 16S rRNA, STY2020, and STY2021 were 1,326 bp, $429 \mathrm{bp}$, and $732 \mathrm{bp}$, respectively.

pathogenicity remains unknown. More importantly, antigenicity prediction scores using SCRATCH protein prediction software [26] showed that genes STY0201, STY0207, STY0307, STY0326, and STY2020 were highly antigenic and may have potential to serve as antigens for serodiagnosis of typhoid fever (Table 3). When compared with the deduced amino acid sequence of $S$. Paratyphi A, which is the closest relative of S. Typhi [37], the putative proteins showed weak or no similarity to $S$. Typhi (Table 3 ). These findings provide an opportunity for gene cloning and protein expression to investigate their serodiagnostic value for development of lowcost antibody-based diagnostic tests or vaccines for typhoid fever.

In conclusion, 5 S. Typhi-specific genes, namely, STY0307, STY0322, STY0326, STY2020, and STY2021, were found to be highly conserved among $S$. Typhi strains. Wet-lab experiments found no false positive reaction with non-Typhi serotypes or non-Salmonella enteric pathogens. These genes could serve as useful diagnostic markers for development of DNA-based diagnostics for sensitive and specific detection of typhoid fever.

\section{Competing Interests}

The authors declare there is no conflict of interests regarding the publication of this paper.

\section{Acknowledgments}

This work was supported by Universiti Sains Malaysia (USM) Research University Individual (RUI) Grant 
(1001/CIPPM/812096) and the Ministry of Higher Education Prototype Research Grant Scheme (PRGS) (203/CIPPM/ $6740030)$. Yuan Xin Goay was a recipient of the National Science Fellowship (NSF) (M/0071/03/2010/S\&T) and USM Fellowship [P-NFD0004/12(R)]. The authors would like to thank the Department of Clinical Microbiology and Parasitology, Hospital Universiti Sains Malaysia (HUSM), and INFORMM Biobank, Kelantan, Malaysia, for providing the bacterial strains.

\section{References}

[1] M. Akiba, M. Kusumoto, and T. Iwata, "Rapid identification of Salmonella enterica serovars, typhimurium, choleraesuis, infantis, hadar, enteritidis, dublin and gallinarum, by multiplex PCR," Journal of Microbiological Methods, vol. 85, no. 1, pp. 9-15, 2011.

[2] G. C. Buckle, C. L. Walker, and R. E. Black, "Typhoid fever and paratyphoid fever: systematic review to estimate global morbidity and mortality for 2010," Journal of Global Health, vol. 2, article 10401, 2012.

[3] T. C. Darton, C. J. Blohmke, and A. J. Pollard, "Typhoid epidemiology, diagnostics and the human challenge model," Current Opinion in Gastroenterology, vol. 30, no. 1, pp. 7-17, 2014.

[4] J. N. Ja’afar, Y. X. Goay, N. F. Mohammed Zaidi et al., "Epidemiological analysis of typhoid fever in Kelantan from a retrieved registry," Malaysian Journal of Microbiology, vol. 9, no. 2, pp. 147-151, 2013.

[5] T. V. T. Nga, A. Karkey, S. Dongol et al., “The sensitivity of realtime PCR amplification targeting invasive Salmonella serovars in biological specimens," BMC Infectious Diseases, vol. 10, article $125,2010$.

[6] M. D. Ganjali, P. Abdeshahian, K. Sudesh, and K. K. Phua, "Optimization of Salmonella Typhi biofilm assay on polypropylene microtiter plates using response surface methodology," Biofouling, vol. 32, no. 4, pp. 477-487, 2016.

[7] S. A. Zaki and S. Karande, "Multidrug-resistant typhoid fever: a review," Journal of Infection in Developing Countries, vol. 5, no. 5, pp. 324-337, 2011.

[8] A. I. Ugochukwu, O. C. Amu, and M. A. Nzegwu, "Ileal perforation due to typhoid fever-review of operative management and outcome in an urban centre in Nigeria," International Journal of Surgery, vol. 11, no. 3, pp. 218-222, 2013.

[9] M. Hayashi, T. Natori, S. Kubota-Hayashi et al., "A new protocol to detect multiple foodborne pathogens with PCR dipstick DNA chromatography after a six-hour enrichment culture in a broad-range food pathogen enrichment broth," BioMed Research International, vol. 2013, Article ID 295050, 10 pages, 2013.

[10] G. Kumar, C. B. Pratap, O. P. Mishra, K. Kumar, and G. Nath, "Use of urine with nested PCR targeting the flagellin gene (fliC) for diagnosis of typhoid fever," Journal of Clinical Microbiology, vol. 50, no. 6, pp. 1964-1967, 2012.

[11] J. Wang, Z. Q. Xu, P. H. Niu et al., "A two-tube multiplex reverse transcription PCR assay for simultaneous detection of viral and bacterial pathogens of infectious diarrhea," BioMed Research International, vol. 2014, Article ID 648520, 9 pages, 2014.

[12] K. Hirose, K.-I. Itoh, H. Nakajima et al., "Selective amplification of tyv (rfbE), prt (rfbS), viaB, and fliC genes by multiplex PCR for identification of Salmonella enterica serovars Typhi and
Paratyphi A," Journal of Clinical Microbiology, vol. 40, no. 2, pp. 633-636, 2002.

[13] J.-H. Song, H. Cho, M. Y. Park, D. S. Na, H. B. Moon, and C. H. Pai, "Detection of Salmonella typhi in the blood of patients with typhoid fever by polymerase chain reaction," Journal of Clinical Microbiology, vol. 31, no. 6, pp. 1439-1443, 1993.

[14] S. Kolyva, H. Waxin, and M. Y. Popoff, "The Vi antigen of Salmonella typhi: molecular analysis of the viaB locus," Journal of General Microbiology, vol. 138, no. 2, pp. 297-304, 1992.

[15] G. Frankel, S. M. Newton, G. K. Schoolnik, and B. A. Stocker, "Intragenic recombination in a flagellin gene: characterization of the H1-j gene of Salmonella typhi," The EMBO Journal, vol. 8, pp. 3149-3152, 1989.

[16] H. M. Seth-Smith, “SPI-7: salmonella's Vi-encoding Pathogenicity Island," Journal of Infection in Developing Countries, vol. 2, no. 4, pp. 267-271, 2008.

[17] E. M. Daniels, R. Schneerson, W. M. Egan, S. C. Szu, and J. B. Robbins, "Characterization of the Salmonella paratyphi C Vi polysaccharide," Infection and Immunity, vol. 57, pp. 3159-3164, 1989.

[18] A. Kumar, Y. Balachandran, S. Gupta, S. Khare, and Suman, "Quick PCR based diagnosis of typhoid using specific genetic markers," Biotechnology Letters, vol. 32, no. 5, pp. 707-712, 2010.

[19] S. Khan, B. N. Harish, G. A. Menezes, N. S. Acharya, and S. C. Parija, "Early diagnosis of typhoid fever by nested PCR for flagellin gene of salmonella enterica serotype typhi," Indian Journal of Medical Research, vol. 136, no. 5, pp. 850-854, 2012.

[20] P. G. Agron, R. L. Walker, H. Kinde et al., "Identification by subtractive hybridization of sequences specific for salmonella enterica serovar enteritidis," Applied and Environmental Microbiology, vol. 67, no. 3-12, pp. 4984-4991, 2001.

[21] P. Leekitcharoenphon, E. M. Nielsen, R. S. Kaas, O. Lund, and F. M. Aarestrup, "Evaluation of whole genome sequencing for outbreak detection of Salmonella enterica," PLoS ONE, vol. 9, no. 2, Article ID e87991, 2014.

[22] S. Porwollik, R. M.-Y. Wong, and M. McClelland, "Evolutionary genomics of Salmonella: gene acquisitions revealed by microarray analysis," Proceedings of the National Academy of Sciences of the United States of America, vol. 99, no. 13, pp. 8956-8961, 2002.

[23] F. Poly, D. Threadgill, and A. Stintzi, "Identification of Campylobacter jejuni ATCC 43431-specific genes by whole microbial genome comparisons," Journal of Bacteriology, vol. 186, no. 14, pp. 4781-4795, 2004.

[24] J. R. Marchesi, T. Sato, A. J. Weightman et al., "Design and evaluation of useful bacterium-specific PCR primers that amplify genes coding for bacterial 16S rRNA," Applied and Environmental Microbiology, vol. 64, no. 2, pp. 795-799, 1998.

[25] N. F. Kamaruzzaman, N. J. Jaafar, M. H. Hani et al., "Pulsed-field gel electrophoresis analysis of Salmonella enterica serovar typhi isolates in the north-east region of Peninsular Malaysia between 2002 and 2009," Journal of Applied Life Sciences International, vol. 5, no. 2, pp. 2394-1103, 2016.

[26] C. N. Magnan, M. Zeller, M. A. Kayala et al., "High-throughput prediction of protein antigenicity using protein microarray data," Bioinformatics, vol. 26, no. 23, pp. 2936-2943, 2010.

[27] J. Parkhill, G. Dougan, K. D. James et al., "Complete genome sequence of a multiple drug resistant Salmonella enterica serovar Typhi CT18," Nature, vol. 413, no. 6858, pp. 848-852, 2001.

[28] W. Deng, S.-R. Liou, G. Plunkett III et al., "Comparative genomics of Salmonella enterica serovar Typhi strains Ty2 and CT18," Journal of Bacteriology, vol. 185, no. 7, pp. 2330-2337, 2003. 
[29] S. Y. Ong, C. B. Pratap, X. Wan et al., "Complete genome sequence of Salmonella enterica subsp. Enterica serovar typhi P-stx-12," Journal of Bacteriology, vol. 194, no. 8, pp. 2115-2116, 2012.

[30] D. Xu, J. O. Cisar, F. Poly et al., "Genome sequence of Salmonella enterica serovar Typhi oral vaccine strain Ty21a," Genome Announcements, vol. 1, no. 4, Article ID e00650-13, 2013.

[31] S. M. Harish, K. S. Sim, F. Mohd Nor et al., "Complete genome sequence of Salmonella enterica subsp. enterica serovar Typhi isolate B/SF/13/03/195 associated with a Typhoid carrier in pasir mas, Kelantan, Malaysia," Genome Announcements, vol. 3, no. 6, Article ID e01285-15, 2015.

[32] S. Muhamad Harish, K.-S. Sim, N. Najimudin, and I. Aziah, "Genome sequence of Salmonella enterica subsp. enterica serovar Typhi isolate PM016/13 from untreated well water associated with a typhoid outbreak in pasir mas, Kelantan, Malaysia," Genome Announcements, vol. 3, no. 6, Article ID e01261-15, 2015.

[33] B. D. Cobb and J. M. Clarkson, "A simple procedure for optimising the polymerase chain reaction (PCR) using modified Taguchi methods," Nucleic Acids Research, vol. 22, no. 18, pp. 3801-3805, 1994.

[34] C.-C. Chang, C.-C. Chen, S.-C. Wei, H.-H. Lu, Y.-H. Liang, and C.-W. Lin, "Diagnostic devices for isothermal nucleic acid amplification," Sensors (Switzerland), vol. 12, no. 6, pp. 83198337, 2012.

[35] C. B. Pratap, G. Kumar, S. K. Patel et al., "Targeting of putative fimbrial gene for detection of $S$. typhi in typhoid fever and chronic typhoid carriers by nested PCR," Journal of Infection in Developing Countries, vol. 7, no. 7, pp. 520-527, 2013.

[36] G. J. Yin Ngan, L. M. Ng, R. T. P. Lin, and J. W. P. Teo, "Development of a novel multiplex PCR for the detection and differentiation of Salmonella enterica serovars Typhi and Paratyphi A," Research in Microbiology, vol. 161, no. 4, pp. 243248, 2010.

[37] K. E. Holt, N. R. Thomson, J. Wain et al., "Pseudogene accumulation in the evolutionary histories of Salmonella enterica serovars Paratyphi A and Typhi," BMC Genomics, vol. 10, article 36, 2009. 

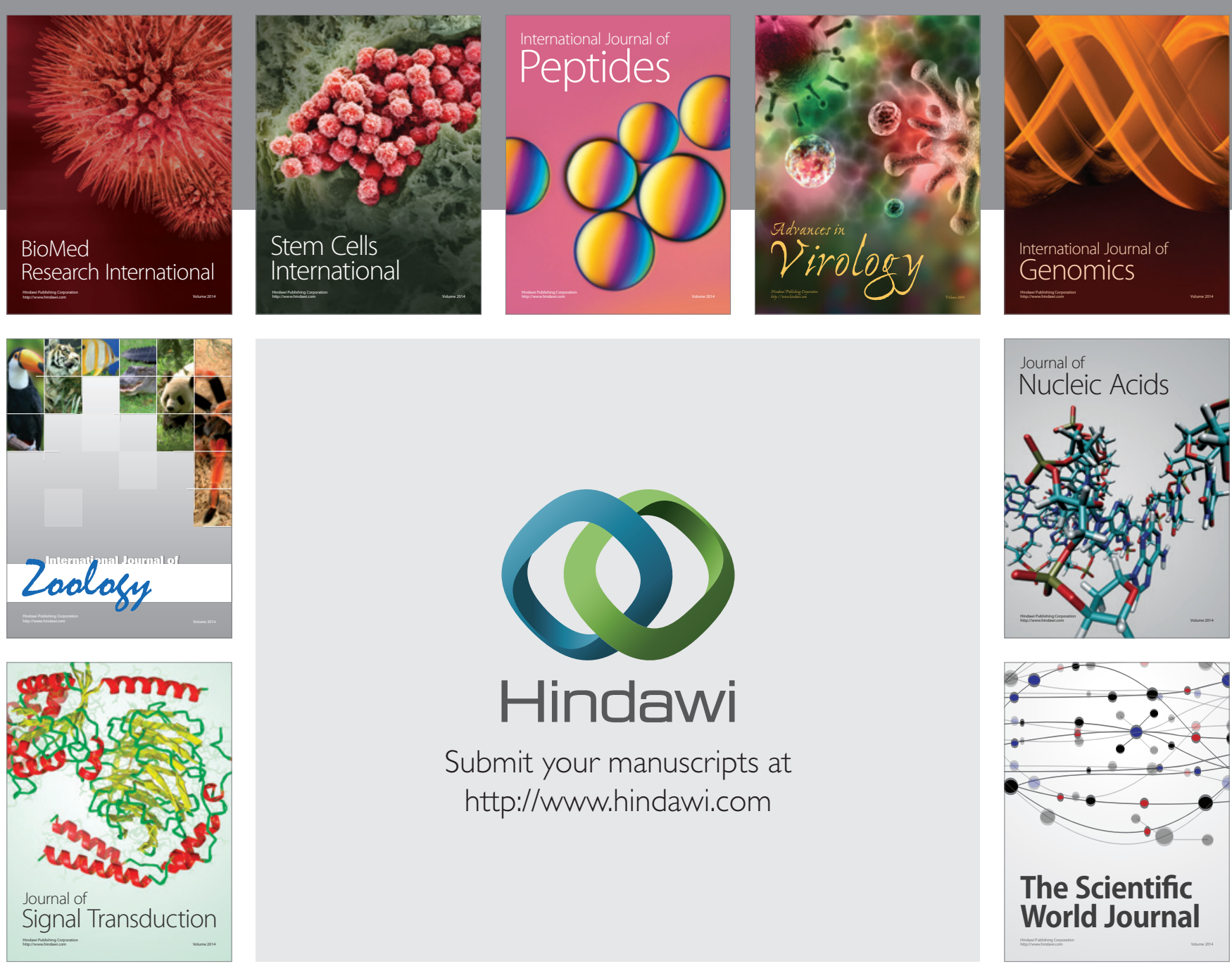

Submit your manuscripts at

http://www.hindawi.com
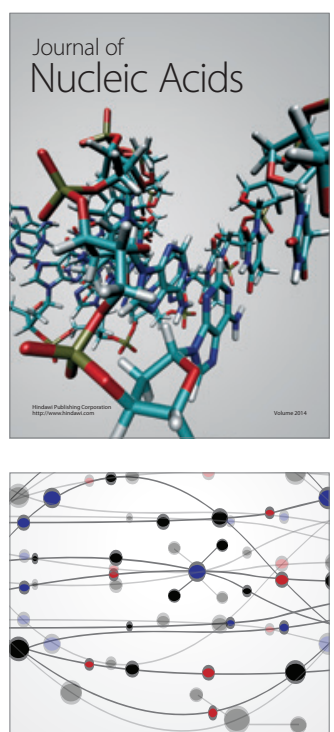

The Scientific World Journal
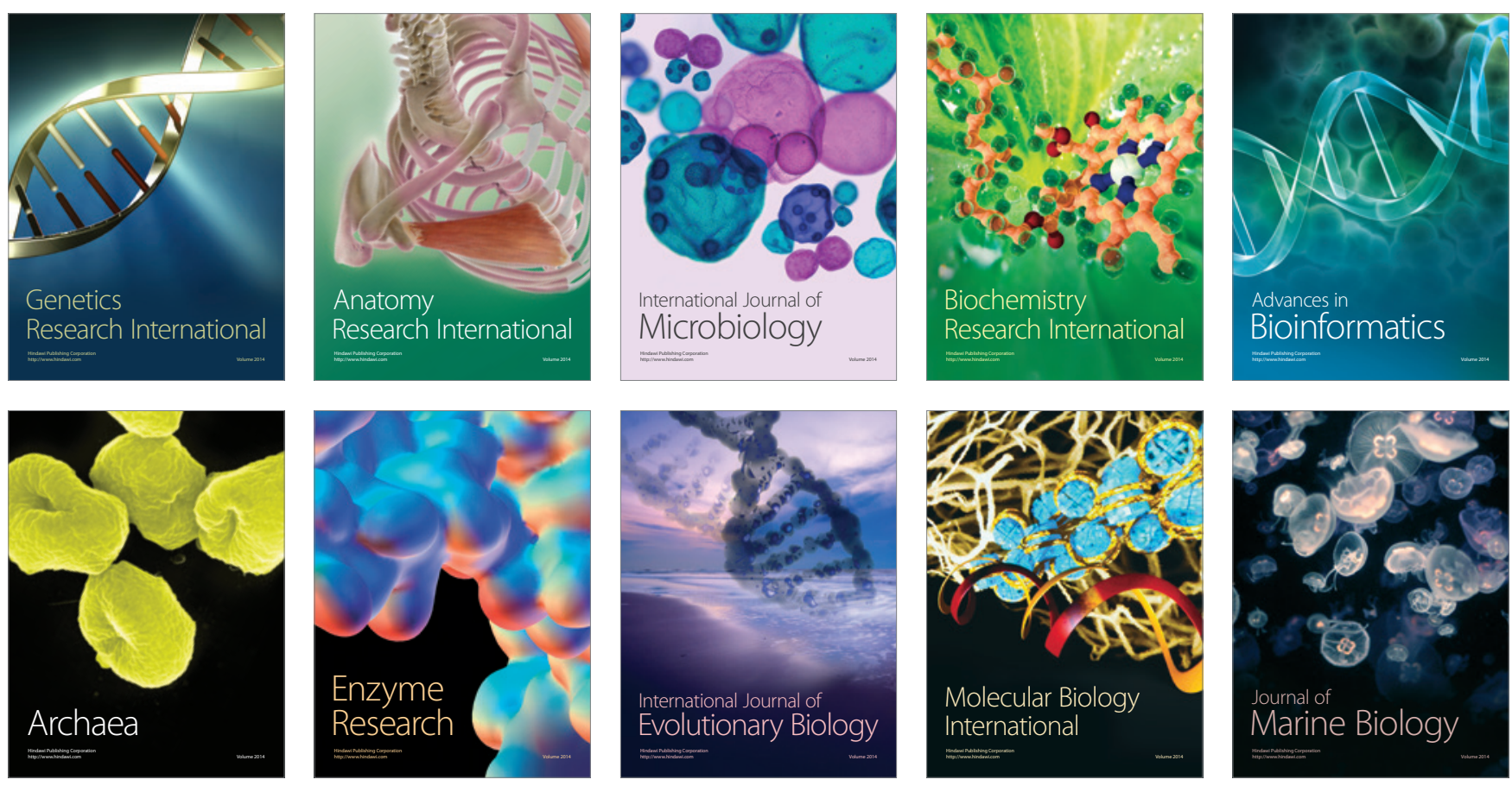